\title{
Influences of Trace Water on Electrochemical Performances for Lithium Ion Batteries
}

\author{
Chunlei $\mathrm{Li}^{1, \mathrm{a}}$, Fengjuan Tang ${ }^{1, \mathrm{~b}}$,Shiyou $\mathrm{Li}^{1, \mathrm{c}}$ \\ ${ }^{1}$ Lanzhou University of Technology, Lanzhou 730050, China; \\ a1489283953@qq.com, ${ }^{\text {b7377781767@qq.com, }{ }^{\text {c}} 191348761 @ q q . c o m}$
}

Keywords: lithium ion batteries, trace water, electrolyte, electrochemical performances.

\begin{abstract}
The influences of trace water on electrochemical performances for lithium ion batteries are investigated by adjusting the trace water in the electrolyte. Electrochemical performances and AC impedance spectra are tested after the first process of lithiation. Results indicate that the battery comprehensive electrochemical properties change little when the water content is less than 211.3 ppm in electrolyte, however, the battery capacity attenuates when the water content is more than $211.3 \mathrm{ppm}$, results that the impedance increases sharply.
\end{abstract}

\section{Introduction}

Lithium ion batteries are expected to be large-scale applications in electric cars and solar energy reserves. Water is the key factor needed to be strictly controlled for lithium ion battery in the production process. Not only resulting lossing of the irreversible capacity [1], impacting seriously on internal resistance of battery and forming of solid electrolyte interphase (SEI) layer [2, 4], but also corroding fluid and cathode materials, result in reducing cycling performance and Stability of battery When trace water is exist $[5,6]$. Therefore, the environment humidity, anode materials and water content of the electrolyte must be controlled strictly for the preparation process of lithium ion battery. While less attention was devoted to the researching on the effects of trace water on performance of battery at present. In this paper, the influences of trace water on electrochemical performances for lithium ion batteries are investigated by adjusting the trace water in the electrolyte.

\section{Experimental}

The MCMB electrode was composed of 84 wt. $\%$ MCMB powder, 8 wt. $\%$ carbon black and 8 wt. $\%$ poly (vinylidene fluoride). The positive electrode was composed of $\mathrm{LiMn}_{2} \mathrm{O}_{4}(84 \mathrm{wt} . \%)$, acetylene black (8 wt.\%) and PVDF (8 wt.\%). The $\mathrm{LiMn}_{2} \mathrm{O}_{4}$ anode material was prepared in our own laboratory. $1 \mathrm{~mol} / \mathrm{L} \mathrm{LiPF}_{6}-\mathrm{EC} / \mathrm{DEC}$ electrolyte was produced by chaoyang yongheng chemical Co. Ltd. Adding different trace water in the electrolyte to make the water content in electrolyte retain at $82.8 \mathrm{ppm}$ (w-a), $129.1 \mathrm{ppm}(\mathrm{w}-\mathrm{b}), 211.3 \mathrm{ppm}$ (w-c), $302.4 \mathrm{ppm}(\mathrm{w}-\mathrm{d}), 412.1 \mathrm{ppm}$ (w-e) and 525.5 ppm (w-f), respectively. Trace water in the electrolyte was achieved by Karl fischer moisture Titrator (KF756) test. Experimental cells were assembled in an argon atmosphere glove box using the above prepared $\mathrm{LiMn}_{2} \mathrm{O}_{4}$ and MCMB electrode which acted as cathode, and the lithium sheet as the anode material. Furthermore, different water content of $\mathrm{LiPF}_{6}-\mathrm{EC} / \mathrm{DEC}$ was as the electrolyte, and Anda celgard porous polypropylene was as the separator. Electrochemical performances and AC impedance spectra were tested after the first lithiation process. Electrochemical performance tests of cells were performed on a LAND CT2001A tester (Wuhan, China) at room temperature $\left(10^{\circ} \mathrm{C}\right)$. The AC impedance spectra and electrochemical window measurements were carried out on an electrochemical work station CHI 660C (Shanghai, China). Ionic conductivity tests of electrolyte were performed on a conductivity meter DDS-307 (shanghai, china) at room temperature $\left(10{ }^{\circ} \mathrm{C}\right)$. 


\section{Results and discussion}

Electrochemical window and Ionic conductivities of six different electrolytes. Figure 1a shows the electrochemical window of the different water content electrolytes. All the test conditions are kept to be the same, electrochemical workstation test voltage ranges from $3 \mathrm{~V}$ to $6.5 \mathrm{~V}$, and scan rate is $0.01 \mathrm{mV} \mathrm{s}^{-1}$. The test results show that the trace water in electrolyte have no obviously effect on electrolyte electrochemical window. Figure $2 \mathrm{~b}$ shows Ionic conductivity of different electrolytes at $10^{\circ} \mathrm{C}$. There are trace water in the range of $82.8 \mathrm{ppm}$ to $525.5 \mathrm{ppm}$, with the increase of water content, the ionic conductivity increases significantly. This may be due to the low viscosity of water, which reduces the resistance of lithium ion migration.
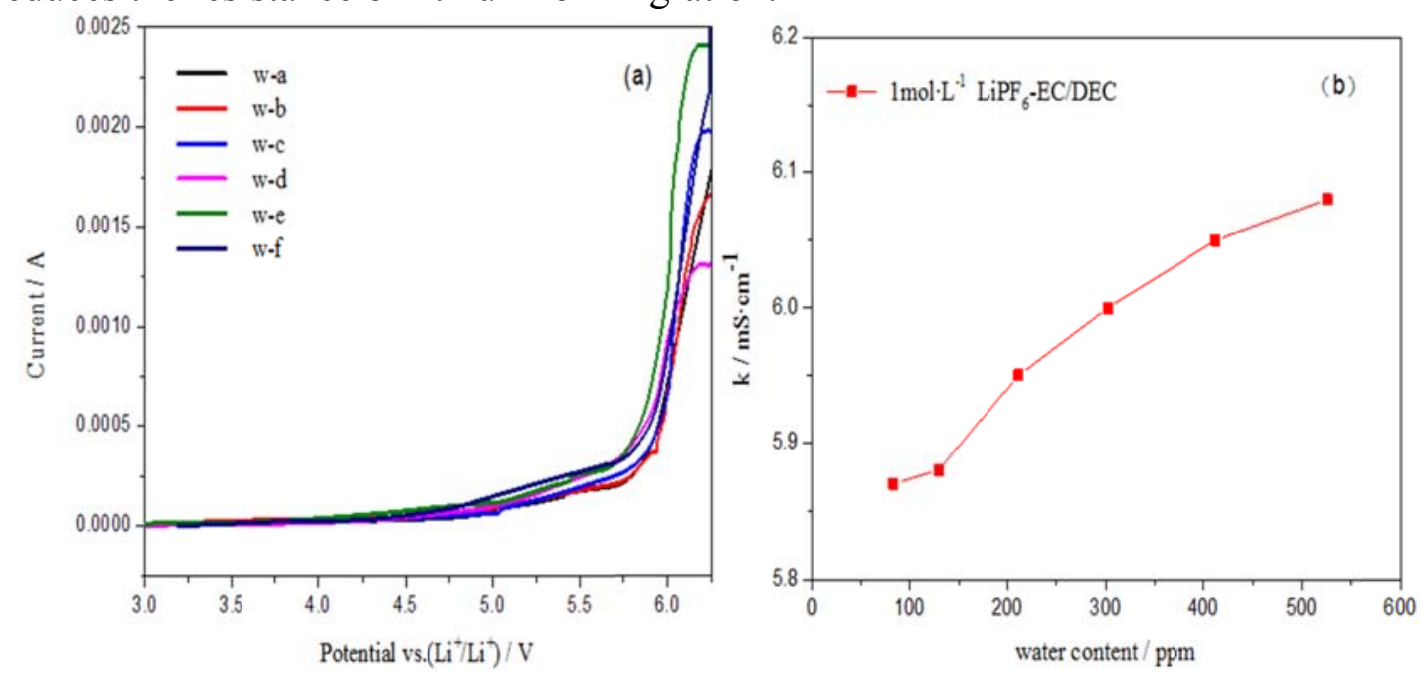

Fig.1. Influences of trace water on electrolyte electrochemical window and ionic conductitive for (a)

The electrochemical window of the six different kinds of electrolytes; (b) Ionic conductivity of different electrolytes;

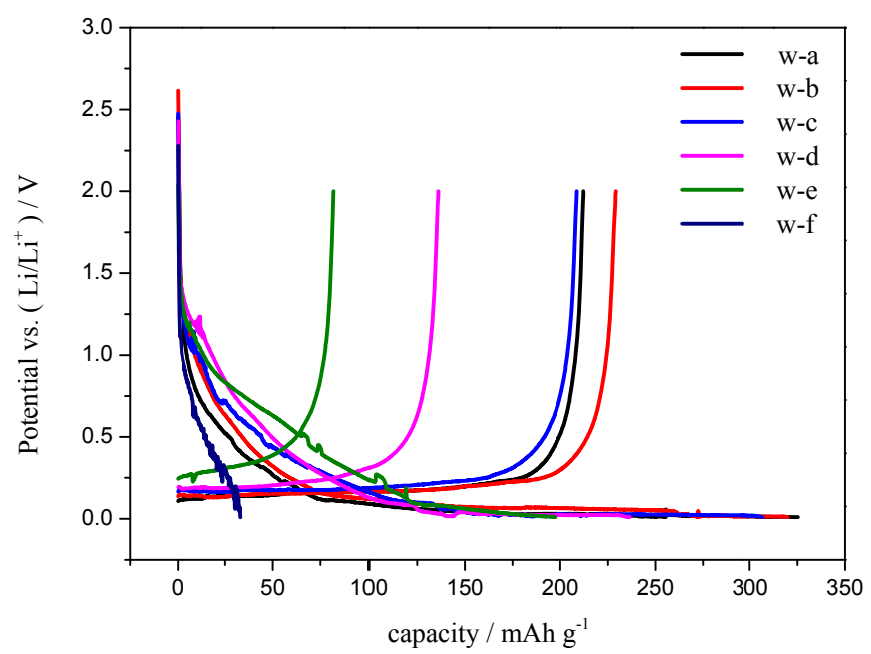

Fig.2. The first discharge-charge curves of Li/MCMB half-cells with six electrolytes.

Electrochemical performances of $\mathrm{Li} / \mathbf{M C M B}$ cells. Figure 2 shows the first discharge-charge curves of Li/MCMB half-cells with six electrolytes, when the water content of the electrolyte is retained at $82.8 \mathrm{ppm}, 129.1 \mathrm{ppm}, 211.3 \mathrm{ppm}, 302.4 \mathrm{ppm}, 412.1 \mathrm{ppm}$ and $525.5 \mathrm{ppm}$, the first discharge capacity of Li/MCMB half-cells is $325.4 \mathrm{mAh} \mathrm{g}^{-1}, 320 \mathrm{mAh} \mathrm{g}$, $306.6 \mathrm{mAh} \mathrm{g}^{-1}, 236.5$ $\mathrm{mAh} \mathrm{g}^{-1}, 197.4 \mathrm{mAh} \mathrm{g}^{-1}$, and $33.1 \mathrm{mAh} \mathrm{g}^{-1}$, respectively. It can be seen form Figure 2 that the water content of electrolytes ranges from $82.8 \mathrm{ppm}$ to $211.3 \mathrm{ppm}$, the first discharge capacity slightly decreases. However, with the water content increasing, more than $211.3 \mathrm{ppm}$, the first discharge capacity significantly decreases with increasing of moisture content. There are two factors proposed to explain the decrease of the first discharge capacity in this figure: ( I ) the formation of SEI film 
has consumed part of $\mathrm{Li}^{+}$[2], and ( II ) if the formation of SEI film have finished, there is still some trace water in the electrolyte, $\mathrm{H}_{2} \mathrm{O}$ will prompt $\mathrm{LiPF}_{6}$ decomposes into $\mathrm{POF}_{3}$ and $\mathrm{LiF}$. Their reaction mechanism is shown as follows [7],

$$
\begin{array}{ll}
\text { ( I ) } \mathrm{EC}+\mathrm{Li}^{+}+\mathrm{e} \rightarrow \mathrm{ROCO}_{2} \mathrm{Li}+\mathrm{ROH}, & 2 \mathrm{ROCO}_{2} \mathrm{Li}+\mathrm{H}_{2} \mathrm{O} \rightarrow \mathrm{Li}_{2} \mathrm{CO}_{3}+\mathrm{CO}_{2}+2 \mathrm{ROH}, \\
\text { ( II ) } \mathrm{LiPF}_{6} \rightarrow \mathrm{LiF}+\mathrm{PF}_{5}, & \mathrm{PF}_{5}+\mathrm{H}_{2} \mathrm{O} \rightarrow \mathrm{POF}_{3}+2 \mathrm{HF} .
\end{array}
$$

Therefore, the trace water is less than $211.3 \mathrm{ppm}$, mechanism ( I ) plays a leading role, when trace water is more than $211.3 \mathrm{ppm}$, mechanism (II) plays a leading role. so in the range of 211.3 ppm to $525.5 \mathrm{ppm}$, the $\mathrm{Li}^{+}$was consumpted increasely leading to the decrease of the discharge capacity.

Impedance characteristics of $\mathrm{Li} / \mathrm{MCMB}$ cells during the first lithiation process. The relationship between water content and impedance is shown in figure 3. Trace water has a significant influence on the impedance, with the increasing of water content, impedance increases significantly. Because the aforementioned excessive trace water in the electrolyte induces decomposition reaction, it produces more insoluble lithium salts such as $\mathrm{POF}_{3}, \mathrm{LiF}$ and so on, which deposite on the SEI surface results in the increased impedance.

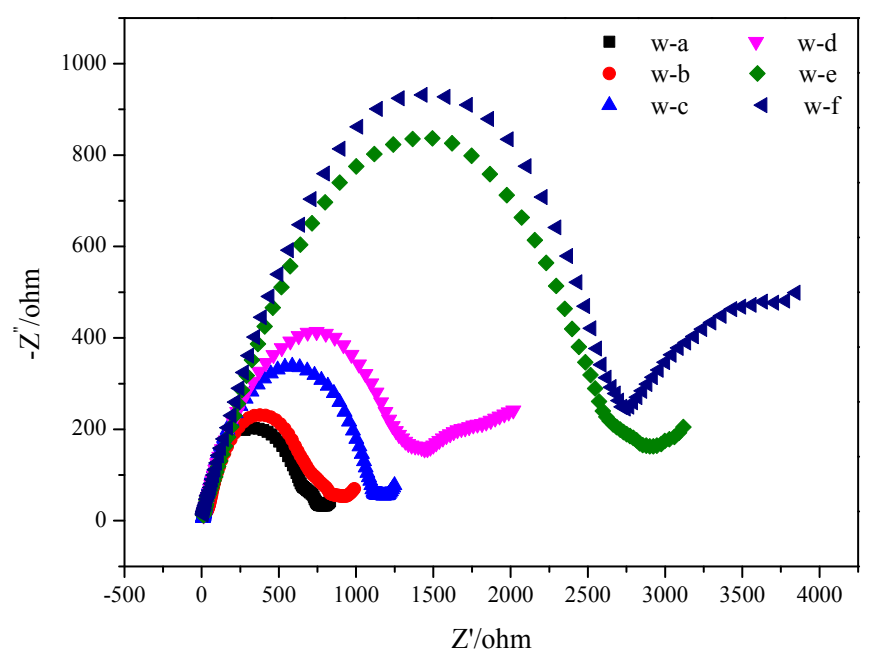

Fig.3. The EIS spectra of Li/MCMB cells with six electrolytes during the first lithiation process.

Electrochemical performances of $\mathrm{LiMn}_{2} \mathrm{O}_{4} / \mathrm{Li}$ cells. Figure 4a shows that when the trace water is less than $211.3 \mathrm{ppm}$, the capacity retention rate is more than $85 \%$ after 100 cycles. However, when the water content is higher than $211.3 \mathrm{ppm}$, the cell cycle performance seriously attenuates with capacity retention of less than $70 \%$ after 100 cycles. The attenuate capacity is due to the corrosion effect on electrode materials which the reaction between trace of water and lithium salt produces $\mathrm{HF}$ and $\mathrm{PF}_{5}$. As shown in figure 4b, when the trace water is $82.8 \mathrm{ppm}, 129.1 \mathrm{ppm}$ and $211.3 \mathrm{ppm}$, there are no obvious differences in the Mean voltages. Conversely, when the trace water continues to increase, a sharp drop appeared in Mean voltages. The results may be due to the increase in polarization impedance of electrode, which hinders the embedding and discharging of lithium ion. 

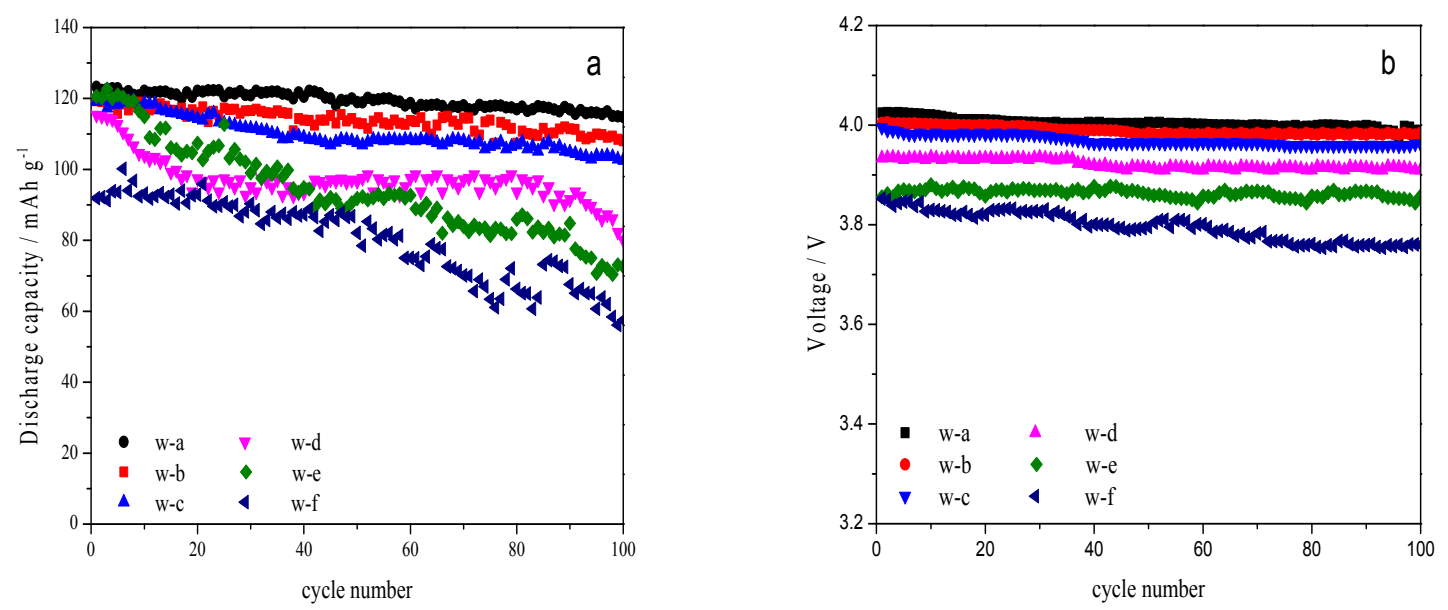

Fig.4. cycling performances and Mean voltages of $\mathrm{LiMn}_{2} \mathrm{O}_{4} / \mathrm{Li}$ half-cells with six different electrolytes recorded at $0.2 \mathrm{C}$, respectively (a) discharge capacity vs. cycle number; (b) Mean voltages vs. cycle number.

\section{Conclusions}

Water is the key factor needed to be strictly controlled for lithium ion battery in the production process. In this paper, the influences of trace water on electrochemical performances for lithium ion batteries are investigated by adjusting the trace water in the electrolyte. The results demonstrate that the trace water in electrolyte has an important influence on electrochemical performance of battery. The critical value of water content in electrolyte is $211.3 \mathrm{ppm}$, the electrolyte with high water content leads to serious attenuation of electrochemical performance and is responsible for the sharply increased battery impedance.

\section{Acknowledgement}

4)

This work was supported by the Natural Science Foundation of China(no.21406100 and 5150212

\section{References}

[1] F. Huang, Y. H. Zhou, Review of electrolytes for lithium-ion batteries. J. Battery Bimonthly (In Chinese).Vol. 31(2001)No.6,p.290-293.

[2] M. B. Pinson, Theory of SEI formation in rechargeable batteries: capacity Fade, accelerated aging and lifetime prediction. J. Electrochemical Societ. Vol.160(2013)No.2,p.A243-A246.

[3] G. X. Hu, J. Y. Xie, The influencing factors of lithium ion battery safety. J. Electrochemistry (In Chinese). Vol.8(2002)No.3,p.123-126.

[4] M. Y. Nie, Role of lithium salt on solid electrolyte interface (SEI) formation and structure in lithium ion batteries. J. Electrochemical Society. Vol.161(2014)No.6,p.A1001-A1006.

[5] D. aurbach, W. eissman, A. zaban, et al. on the role of water contamination in rechargeable Li batteries. J. Electrochimica Acta. Vol.45(1999),p.1135-1140.

[6] U. heider, R. oesten, M jungnitz, Challenge in manufacturing electrolyte solutions for lithium and lithium ion batteries quality control and minimizing contamination level. J. Journal of Power Sources.Vol. 81(1999).p.199-122.

[7] X. Z. Yu, H. H. Zheng, Research progress on compatibility of electrolyte with carbon negative electrode in lithium ion batteries. J. Journal of Power Sources. Vol.24(2002)No.3,p.171-177. 